\title{
Research on dynamic pricing of perishable products under uncertain consumer demand
}

\author{
Li Zhou ${ }^{1, *}$, Jing $\mathbf{L i}^{2}$ \\ ${ }^{1}$ School of Information, Beijing Wuzi University, Beijing, China \\ ${ }^{2}$ Graduate department, Beijing Wuzi University, Beijing, China \\ Email address: \\ zhoulibit@126.com (Li Zhou)
}

To cite this article:

Li Zhou, Jing Li. Research on Dynamic Pricing of Perishable Products under Uncertain Consumer Demand. Journal of Finance and Accounting. Vol. 2, No. 4, 2014, pp. 90-94. doi: 10.11648/j.jfa.20140204.11

\begin{abstract}
It mainly focuses the consumer strategy behavior effect on retailers pricing mechanism. Under the condition of uncertainty demand, consumers' strategy behavior influence to price and profit. By introducing a discount factor, considering inventory timely complement and fixed inventory in two cases, obtains purchase decision and dynamic pricing strategies of consumers.
\end{abstract}

Keywords: Consumer Strategy, Perishable Products, Dynamic Pricing, Inventory

\section{Introduction}

When the market information environment is sufficient, the consumers purchase goods will be very rational. They through the commercial history information, inventory and sales cycle of perishable products price changes have certain expectations, then consumers will be rational in that can get the big consumer surplus buying goods. Choice in the maximum consumer surplus let consumers wait for the actual phenomenon buy better explain; such enterprises can provide better reference in the process of practical strategies.

You and Chen (2007)[1] discusses the perishable product ordering strategy and dynamic pricing problems. They divides the sales cycle into two stages, one stage is ahead of the pre-sale stage, at this stage of the sale products not allowed to return. The next stage is the normal marketing stage. In this stage the purchase of goods can enjoy the return service, so can't return in advance sales, and can lock a part number product sales, reduce the risks of enterprises.

For perishable goods order strategy problem, Ringbom and Shy (2008) [2] studies this problem based on the entire industry, discusses the collaborative returns within the industry, and compared the complete, return policy perfect competition and semi Alliance Service provider. Cachon and Swinney (2009b) [3] describes the consumer strategy behavior, and that the non-strategic consumers refers to the decision only to buy or out of the market, and consumers will choose when to buy strategic. Non-strategic consumers into the market, consumer surplus is greater than zero, would choose to buy; if the consumer surplus is less than zero, it will choose to wait. While consumers will compare the whole strategy of perishable goods sales cycle to obtain the consumer surplus, the final choice can obtain maximum consumer surplus time to buy the product.

In theory, Elmaghraby (2003)[4] considers two kinds of conditions of complete and incomplete information. He establishes a model to study the consumers will buy multiple enterprises products, and the price strategy. With the rapid development of internet transactions, transaction prices, inventories and consumer psychological changes very fast. Zhou(2005)[5] under the condition of complete information, considers the consumer's strategic behavior, further expands the revenue management, and in the continuous time formulates the optimal purchasing strategy. Because the perishable goods value along with the sales cycle of growth, there will be a certain elapse, Aviv (2008)[6] by considering the introduction of a decrements value function of consumer about time, discusses enterprises implement the pricing strategy with fixed inventory.

Peng Zhiqiang(2008)[7] introduces the thought of consumers deciding the transaction price to the revenue management, establish the service provider two period 
pricing model based on customer pricing models, studies show that consumer heterogeneity affects the dynamic pricing strategy of the service provider. On the assumption that consumers are heterogeneous value of product, when consumers value less than the price of new products, may buy remanufactured products,

Peng Zhiqiang (2009a)[8] studies one kind differential pricing model based on the re-manufacturing and consumer waiting behavior. Research shows that the optimal pricing decisions and profits are influenced by the manufacturing cost and the consumer waiting behavior.

Based on the previous research, consumer behavior has become one of the most important factors that affect pricing mechanism. The focus of this paper is mainly study on influencing factors of consumer strategy behavior of retailers pricing mechanism. Specifically, under uncertainty demand situation, influence strategy behavior of consumers on the prices and profits; and by introducing a discount factor, considering the inventory quantity and consumer demand for different circumstances, purchase decision and dynamic pricing strategies of consumers.

\section{Factors Affecting the Retailer Gains}

From the economics perspective, there are two factors of product sales price and volume influence retailers' revenue. Other factors can be separately or simultaneously influence these two factors, so as to affect the retailer's revenue indirectly. To analyze the influence factors from the internal environment for retailers: quality, cost, size, price, market share, customer loyalty, the potential market. From the analysis of the external environment, the main factors are: products in the market competition, product substitutability, quality degree of product market and facing environmental laws and regulations.

In order to simplify the analysis, the retailer's fixed cost and variable cost, spread out into a single product is calculated. By considering the dynamic pricing and ordering strategy to influence the retailer's revenue, and then consider ordering strategy leads to inventory and affect the retailer's cost, final income comprehensive analysis of retailers.

If consumers demand function is $D(p)$, is a continuous function with the price of $\mathrm{P}$ real time change, and monotonically decreasing. Assume the sale period into two stages, in the sales cycle, assumes that the product sales price is $p_{1}$, in the period two sales price for $p_{2}$. Because of the existence of value passing, so suppose there are $p_{1} \geq p_{2}$. When the products are remaining, will cause a certain degree of inventory backlog, the backlog of cost is set to $k$, and $p_{1} \geq p_{2} \geq k$, denotes the second stage consumers of goods probability, product inventory is $c$.

\section{Effects of Dynamic Pricing on Income of Perishable Goods under Consumer Strategy Behavior}

\subsection{Effects of Dynamic Pricing in Revenue for Perishable Products}

Characteristics of retailers to sell products with the general merchandise, in accordance with the features of the consumer demand curve in economics, when the product price is lower, more consumers, and the higher the price, demand less. Consumers in the purchase of such products, there is a demand curve. Discuss the influence of dynamic pricing for perishable goods during this process; we do not consider the impact of strategies of consumers.

\subsubsection{When the Demand Function is \\ Linear $D(p)=a-b p$.}

When separate pricing, retailers get the optimal one-time pricing is $p_{0}$, and in this process, ignoring the retailers cost, only consider the benefits of retailers. Returns of retailers is

$$
\pi_{0}=p_{0}\left(a-b p_{0}\right)
$$

Bsed on derivative function available for the one-time pricing, the optimal price is

$$
p_{0}=a / 2 b,
$$

Total revenue is

$$
\pi_{0}=a^{2} / 4 b \text {. }
$$

When the retailers price two stage $\left(p_{1}, p_{2}\right)$, only consider the benefits, ignoring the cost of products, and $p_{1} \geq p_{2}$. The benefit formula for retailers:

$$
\pi_{1}=p_{1}\left(a-b p_{1}\right)+p_{2}\left(\left(a-b p_{2}\right)-\left(a-b p_{1}\right)\right)
$$

According to the partial derivative function of two variables, we can obtain the optimal in the two phase, the pricing combination is $(2 a / 3 b, a / 3 b)$, finally gain is $\pi_{1}=a^{2} / 3 b$, and $\pi_{1}>\pi_{0}$. So retailers can implement the two stages pricing to gain more profit under dynamic pricing situation.

When $n \geq 2$, retailers implement multi-stage pricing $\left(p_{1}, p_{2}, \ldots, p_{n}\right)$, while the benefit formula:

$$
\begin{aligned}
& \pi_{n}=p_{1}\left(a-b p_{1}\right)+p_{2}\left(\left(a-b p_{2}\right)-\left(a-b p_{1}\right)\right)+\cdots+ \\
& p_{n}\left(\left(a-b p_{n}\right)-\left(a-b p_{n-1}\right)\right)
\end{aligned}
$$

According to the partial derivative of multiple function equation, we can obtain the optimal pricing combination for multi-stage is $\left(2 a / 3 b, a / 3 b, \ldots,(1 / 2)^{n-2}(a / 3 b)\right)$.

So gain formula is 


$$
\pi_{0}=2 a^{2} / 9 b+4 a^{2} / 27 b\left(1-(1 / 4)^{n-1}\right) .
$$

The profit ratio to one-stage is $m=\pi_{n} / \pi_{0}$, take value of $n=100$, we can get the ratio $m$ in figure 1 .

\subsubsection{When the Demand Function Curve is $D(p)=a e^{-b p}$}

Similarly, when separate pricing, retailers get the optimal one-time pricing is $p_{0}$, and in this process, ignoring the retailers cost, only consider the benefits of retailers. Returns of retailers is

$$
\pi_{0}=p_{0} a e^{-b p_{0}},
$$

Based on derivative function available for the one-time pricing, the optimal price is $p_{0}=1 / b$, total revenue is

$$
\pi_{0}=a / e^{b} .
$$

When the retailers price two stage $\left(p_{1}, p_{2}\right)$, only consider the benefits, ignoring the cost of products, and $p_{1} \geq p_{2}$. The benefit formula for retailers:

$$
\pi_{1}=p_{1} a e^{-b p_{1}}+p_{2}\left(a e^{-b p_{2}}-a e^{-b p_{1}}\right)
$$

According to the partial derivative function of two variables, we can obtain the optimal in the two phase, the pricing combination is $((1 / b)(2-1 / e),(1 / b)(1-1 / e))$.

And finally gain is

$$
\pi_{1}=a e^{-(1-1 / e)} / b,
$$

Where $\pi_{1}>\pi_{0}$. So retailers can implement the two stages pricing to gain more profit under dynamic pricing situation.

When $n \geq 2$, retailers implement multi-stage pricing $\left(p_{1}, p_{2}, \ldots, p_{n}\right)$, while the benefit formula:

$$
\begin{aligned}
& \pi_{n}=p_{1} a e^{-b p_{1}}+p_{2}\left(a e^{-b p_{2}}-a e^{-b p_{1}}\right)+\cdots+ \\
& p_{n}\left(a e^{-b p_{n}}-a e^{-b p_{n-1}}\right)
\end{aligned}
$$

According to the partial derivative of multiple function equation, we can obtain the optimal pricing combination for multi-stage. Because the expression is complicated, we will set the number of dynamic pricing is four, then can obtain the price of each stage are

$$
\begin{aligned}
& \left(\frac{1}{b}+\frac{1}{b}\left(1-e^{-1}\right)+\frac{1}{b}\left(1-e^{-\left(1-\frac{1}{e}\right)}\right), \frac{1}{b}\left(1-e^{-1}\right)+\frac{1}{b}\left(1-e^{-\left(1-\frac{1}{e}\right)}\right)\right. \\
& +\frac{1}{b}\left(1-e^{-\left(1-e^{-\left(1-\frac{1}{e}\right)}\right)}\right), \frac{1}{b}\left(1-e^{-\left(1-\frac{1}{e}\right)}\right)+\frac{1}{b}\left(1-e^{-\left(1-e^{-\left(1-\frac{1}{e}\right)}\right)}\right) \\
& \left.\frac{1}{b}\left(1-e^{-\left(1-e^{-\left(1-\frac{1}{e}\right)}\right)}\right)\right) .
\end{aligned}
$$

The profit ratio to one-stage is $m=\pi_{n} / \pi_{0}$. Under the assumption of the condition, with the increase of the number of $n, m$ value is also in constant increase, indicate that with the increase in the number of retailers pricing, revenue is increasing.

\section{Dynamic Pricing under Uncertainty Consumer Demand}

Although the market sales of goods has certain rule, but consumers' arrival and buy will appear uncertain situation. Retailers make the two phase of the price according to the maximum profit, and consumers will be based on the price to compare the reservation price of product itself, choose the time of purchase. In the uncertain demand, consumers and retailers are mutual game, we propose the following hypothesis:

(1) Assume the sale period into two stages, in the first sales cycle $[0, T]$, assumes that the product sales price is $p_{1}$, in the period two sales of $[T, 2 T]$, the price is $p_{2}$.

(2) The cost of goods retailers offer is $k$, and $p_{1} \geq p_{2} \geq k$.

(3) The consumer in the first stage arrival rate is $\theta$, and $\theta$ is a constant. Set the number of consumers is $N(\theta)$.

(4) Consumers have different reserve prices, the proportion of higher reserve price consumers is $\beta$, reserve higher value of $V_{H}$, reserve low value of $V_{L}$, and there is $V_{H}>V_{L}$.

When retailers setting two stage prices, they need to consider the consumer's reservation price, to keep higher prices consumer purchase in higher priced stage way, keep lower prices consumer purchase in phase two to buy, so as to obtain more consumer surplus. Set high reserve value consumers passing rate as $\alpha$, low value preservation consumers passing rate change is small that can be neglected. The consumers in second stage of the purchase process, if $p_{2}>V_{L}$, then consumers will not buy, on the contrary, when $p_{2}<V_{L}$, retailers will lose some of the consumer surplus, so retailers in the second stage of the pricing strategy will be $p_{2}=V_{L}$.

\section{Dynamic Pricing Strategy under the Condition of Inventory can be Added}

The inventory can be timely supplement, in the circumstances of $p_{2} \geq k$, the retailer can gain profit, while retailers to meet the needs of the consumers, so that in the first stage and the second stage the probability of consumers getting products is one. The first stage keep pricing to $p_{1}$, the consumers whose product reserve price high can obtain consumer surplus as $V_{H}-p_{1}$. The obtained consumer surplus in stage two is $V_{H}-V_{L}$, consumers did not buy in the first stage while waiting for the second stage to purchase will obtain surplus $\alpha V_{H}-V_{L}$. They can obtain consumer surplus at each stage as shown in "Tab. 1". 
Table 1. Consumer surplus at each stage purchase

\begin{tabular}{lll}
\hline Consumer surplus & Consumer reserve higher price of $V_{H}$ & Consumer reserve higher price of $V_{L}$ \\
\hline The first stage arrived, the first stage to buy & $V_{H}-p_{1}$ & $V_{L}-p_{1}$ \\
The first stage arrived, the second stage to buy & $\alpha V_{H}-V_{L}$ & $V_{L}-p_{1}$ \\
The second stage arrived, the second stage to buy & $\alpha V_{H}-p_{2}$ & $V_{L}-p_{1}$ \\
\hline
\end{tabular}

Let the consumer surplus obtained in the first stage and the second stage consistent Then it need to meet:

$$
V_{H}-p_{1}=\alpha V_{H}-V_{L}=\alpha V_{H}-p_{2} .
$$

A retailer in the first and second stage pricing strategy is:

$$
p_{1}-p_{2}=(1-\alpha) V_{H}
$$

In order to reduce strategic consumers, let high retention value strategies consumers as far as possible to buy goods in the first stage, let consumer's surplus in the first stage is greater than the second stage, the pricing strategy is:

$$
p_{1}-p_{2}<(1-\alpha) V_{H} \text {. }
$$

The retailer's profit is:

$$
\begin{aligned}
\pi_{1}= & \frac{1}{2} p_{1} N F(\beta \theta)+\frac{1}{2} p_{2} N F(\beta \theta) \\
& +p_{2} N F((1-\beta) \theta)-k C
\end{aligned}
$$

Because the inventory can complement, in this case, the retailer will continue to select the minimum number of inventory, for two stage pricing structure strategy, in order to allow consumers to buy goods stay in the first stage, in the two stage pricing, the pricing combination of $\left(p_{1}, p_{2}\right)$, need to meet $p_{1}-p_{2}<(1-\alpha) V_{H}$, at the same time $p_{1} \geq p_{2} \geq k$.

\section{Dynamic Pricing Strategy under Fixed Inventory Condition}

In the fixed inventory condition of $\mathrm{C}$, there will be circumstance of consumers buying nothing. For the high retention value of consumption in the first phase, will compare the consumer surplus of buying now and waiting to buy in the second stage, thus to make a choice.

Because of the uncertainty of demand, in the first stage of selling process, will appear two cases of inventory can meet and cannot meet the high retention value of consumers. When the inventory quantity $C<N(\beta \theta)$, the probability of high reserve value consumption can get goods in the first stage is $C / N(\beta \theta)$; when the inventory quantity $C \geq N(\beta \theta)$, the probability of high reserve value consumption can get goods in the first stage is $100 \%$. So, the probability of high reserve value consumption can get goods in the first stage is:

$$
\begin{aligned}
U_{1}= & P\{C \geq N F(\beta \theta)\} * 100 \% \\
& +P\{C<N F(\beta \theta)\} * C / N F(\beta \theta)
\end{aligned} .
$$

At the same time, the consumer surplus of high reserve value consumers buy goods in first stage is $U_{1}\left(V_{H}-p_{1}\right)$.

When the high reserve value consumers in the first stage wait for purchase in the second stage, if $C \geq N(\beta \theta)$, in the second stage to buy goods with probability of $\min \left\{\frac{C-N F(\beta \theta)}{N F(1-\beta) \theta}, 1\right\}$. The probability of consumer waiting to get commodities until the second stages is:

$$
U_{2}=P\{C \geq N F(\beta \theta)\} * \min \left\{\frac{C-N F(\beta \theta)}{N F(1-\beta) \theta}, 1\right\} .
$$

If when the inventory quantity $C<N(\beta \theta)$, the consumer getting commodity probability in the second stage is zero. Then, the probability of high reserve value consumption can get goods in the second stage is $U_{2}=0$.

At the same time, consumer surplus obtained by high retention value consumer in stage two is $U_{2}\left(V_{H}-V_{L}\right)$, assuming the two stage obtain consumer surplus is the same, then $U_{1}\left(V_{H}-p_{1}\right)=U_{2}\left(V_{H}-V_{L}\right)$.

In this way we can get the first stage of retailers pricing:

$$
p_{1}=V_{H}-\left(V_{H}-V_{L}\right) \frac{U_{2}}{U_{1}} .
$$

According to the pricing formula of retailers, we can get $p_{1}<V_{H}$. Along with the increase of retailer inventory, would allow the probability of consumers to obtain goods at stage two increase, will increase the number of strategy consumers, which requires retailers in much stock situation, reduce the first stage price, so as to avoid losses accumulated to stage two caused by larger inventory.

When the inventory quantity $C<N(\beta \theta)$, retailers can sale all as price of $p_{1}$, get profit of $\pi_{3}=C p_{1}$; When the inventory quantity $C \geq N(\beta \theta)$, the number selling in stage one is $N(\beta \theta)$, while in the second stage to obtain profits for $V_{L} * \min \{(C-N F(\beta \theta)), N F((1-\beta) \theta)\}$. Retailers in these two stages, get the profit value is:

$$
\begin{aligned}
\pi= & p_{1} * \min \{N F(\beta \theta), C\}+p_{2} \min \{(C-N F(\beta \theta)), \\
& N F((1-\beta) \theta)\}-k C
\end{aligned}
$$




$$
\begin{aligned}
& \text { The optimal pricing strategy }\left(p_{1}^{*}, p_{2}^{*}\right) \text { is } \\
& \left(V_{H}-\left(V_{H}-\mathrm{V}_{L}\right) \frac{U_{2}}{U_{1}}, V_{L}\right) \text {. }
\end{aligned}
$$

\section{Conclusion}

Retailers face some strategy consumers; consumers will buy goods according to the maximum utility of two stage process. Because retailers face consumer uncertainty, at the same time, the retailer's inventory is starting from the view of revenue management, if consumers can buy in the second stage that the utility must higher than the first phase purchase utility, but at the same time maybe consumer purchase nothing in the second stages, it will reduce the consumer utility of the second phase purchase. Retailers using two stage pricing model, consider the consumers two stages pricing strategy, change price to change the probability of consumer in the second stage purchase, thus to reduce the consumer's strategic behavior. In the course of this study, the main discuss is about uncertainty consumer demand situation, the retailer is divided into inventory can be added timely manner and cannot timely supplied to discuss.

\section{Acknowledgements}

The study is supported by Beijing Wuzi University scientific research base of science and technology innovation platform of modern logistics, information and control technology research (project code: PXM2014_014214_000086).

\section{References}

[1] You P. S, Chen T C. "Dynamic pricing of seasonal goods with spot and forward purchase demands", Computers and Mathematics with Applications, vol.54,pp490-498, 2007.

[2] Ringbom S. Shy O., "Refunds and collusion in service industries", Journal of Economics and Business, pp. vol.60,pp. 502-516, Jun.2008.

[3] Cachon G P, Swinney R. Purchasing, "Pricing, and Quick Response in the Presence of Strategic Consumers", Management Science, vol.55, pp. 497-511, Mar.2009a.

[4] Elmaghraby W, Keskinocak P., "Dynamic Pricing in the Presence of Inventory Considerations: Research Overview, Current Practices, and Future Directions", Management Science, vol.49, pp.1287-1309, Oct.2003,

[5] Zhou Y, Fan M, Cho M., "On the threshold purchasing behavior of customers facing dynamically priced perishable products", Presentation at Informs Pittsburgh National Meeting, Nov 2006.

[6] Aviv Y, Pazgal A., "Optimal Pricing of Seasonal Products in the Presence of Forward-Looking Consumers", Manufacturing \& Service Operations Management, vol.1,pp.1-21, April 2008.

[7] Peng Zhiqiang, Xiong Zhongkai, Li Hao, "The service provider pricing strategy based on customer pricing model", Statistics \& Decision, vol.273, No.21, pp.169-171, Nov. 2008.

[8] Peng Zhiqiang, Xiong Zhongkai, Li Hao, "Research on Discrimination Pricing Model Based on Remanfacturing and Waiting Behaviour of Customers", Soft Science, vol.23,pp.123-126, March 2009a. 